\title{
Traduzindo Von den ersten drei Essentiis: ilustrando o lugar de Paracelso na história das ciências
}

Joakim Wagner e Paulo Oliveira*

\section{Preâmbulo}

Sintetizamos e retomamos aqui alguns aspectos de pesquisa em andamento na FFLCH/USP, ${ }^{1}$ cujo objetivo é uma tradução comentada de um breve trecho de uma obra vasta, elaborada no séc. XVI e ainda hoje largamente desconhecida do público lusófono interessado em história das ciências - apesar de sua inegável relevância para o entendimento de alguns passos importantes no desenvolvimento de paradigmas contemporâneos. Do ponto de vista dos Estudos da Tradução, trata-se em primeira linha de apresentar um possível caminho para a divulgação dessa obra em português, claramente sem a pretensão de suprir a lacuna como um todo, posto que isso demandaria a tradução de um volume muito maior de textos. Na definição do recorte, certamente pesou a formação e experiência profissional em química de um dos autores, além de outros fatores, em parte de ordem linguística. O efeito esperado é duplo: por um lado, despertar o interesse pelo personagem histórico, resgatando uma figura cuja imagem chega até nós distorcida, não fazendo jus a sua real importância; por outro, mostrar um caminho que pode ser seguido nessa e noutras empreitadas de caráter semelhante, ao propor

\footnotetext{
* Universidade de São Paulo (USP); Universidade de São Paulo (USP) e Universidade Estadual de Campinas (UNICAMP).

${ }^{1}$ Trabalho foi realizado com apoio da Coordenação de Aperfeiçoamento de Pessoal de Nível Superior Brasil (CAPES) - Código de Financiamento 001. Agradecemos a Tinka Reichmann (Universidade de Leipzig, Alemanha), que acompanhou as fases iniciais do projeto. O presente trabalho retoma e sintetiza alguns aspectos de pesquisa de mestrado em andamento na FFLCH/USP cujo objetivo é uma tradução comentada de um breve trecho da obra vasta de Paracelso, elaborada no Séc. XVI e ainda hoje largamente desconhecida do público brasileiro interessado em história da ciência - apesar de sua inegável relevância para o entendimento de alguns passos importantes no desenvolvimento de paradigmas contemporâneos.
} 
uma abordagem tradutória considerada pertinente para casos dessa natureza.

\section{Paracelso - O personagem e seu fazer científico}

Theophrastus Bombast von Hohenheim (1493/1494 - 1541), conhecido principalmente pelo apelido Paracelso, ocupa posição ímpar na história das ciências. Foi importante no estabelecimento da forma moderna da Medicina e no surgimento, a partir da Alquimia, de novas áreas de estudos, como Química, Farmácia, Toxicologia, Mineralogia. Em seu tratado Von der Bergsucht, apresenta não só a primeira descrição formal de uma doença ocupacional, mas também de medidas preventivas (cf. MARX, 1941, p. 960). Foi dos primeiros a associar causalmente quadros psicológicos com certas doenças, atualmente chamadas psicossomáticas (cf. WEBSTER, 1995, p. 107-108), e ainda hoje influencia a Psicologia, via Jung.

Nascido na Suíça, Paracelso iniciou em 1516 prolongadas andanças de percurso incerto - pelo mundo, estabelecendo-se como médico inicialmente em Salzburgo em 1524. Fugiu por se ver suspeito de simpatizar com camponeses rebelados. Chegou a Strasburgo em maio de 1526, sendo nomeado médico da cidade já em dezembro. Essa rápida nomeação é sugestiva da existência de uma reputação muito relevante.

Ao final do ano, foi chamado a Basiléia para tratar o famoso editor Johann Froben - Frobenius (ca. 1460-10/1/1527) - que, após curado, patrocinou a nomeação de Paracelso para o posto de médico da cidade. Tal favorecimento, somado à personalidade e à atuação polêmica de Paracelso, desencadeou acentuada animosidade com a comunidade médica da cidade. Paracelso adotava atitudes consideradas muito provocativas, como proferir palestras na universidade usando o vernáculo, e não o latim, queimar publicamente livros de medicina, criticar ácida e publicamente seus colegas de profissão e, provavelmente a mais séria, opor-se abertamente às figuras tradicionais de autoridade em medicina, como Galeno, Hipócrates e Avicena. Após perder um processo em que cobrava honorários pré-acertados que um cônego se recusara a lhe pagar, Paracelso teve reação explosiva e fugiu às pressas, em fevereiro de 1528, para evitar a prisão. 
Entre 1529 e 1531, Paracelso permaneceu em Nürnberg, onde escreveu a importante obra Paragranurn e novamente se envolveu em grande polêmica. Atacou frontalmente e ridicularizou o uso da madeira guaiaco para tratar sífilis, que se manifestava muito virulentamente na Europa desde 1493. Em seu lugar, preconizava ministração cuidadosamente dosada de mercúrio. Para dimensionar o impacto dessa postura, basta citar que a importação e o comércio de guaiaco eram monopólio da família Fugger, ricos e poderosos banqueiros radicados em Nürnberg.

Após novas andanças, em fins de 1537, novo conflito com a comunidade médica, desta vez em Viena. Isso lhe rendeu a proibição de imprimir sua obra Defensiones nessa cidade (ZEKERT, 1941, p. 292). Chamado pelo príncipe-bispo da cidade, Ernst von Bayern (1500-1560), Paracelso chega a Salzburgo em 5 de agosto de 1541. Em 21 de setembro, registra um testamento e morre três dias depois, aos 48 anos.

Mesmo a causa de sua morte está envolta em polêmica e discussões. As explicações aventadas incluem queda fatal após bebedeira, uma briga em taberna e sequelas dos seus manuseios de produtos perigosos, como arsênico e mercúrio (BERNOULLI, 1994, p. 336; ZEKERT, 1941, p. 294; DEICHMANN, 1986, p. 207; WEBER, 1893, p. 62).

Em suas andanças de juventude, Paracelso foi médico militar, testemunhando a crueza do tratamento dado aos feridos em batalha. Como descreve Stillmann (1917, p. 397), abundavam cauterizações com ferro em brasa ou óleo fervente e a infecção era amplamente encarada como parte da cura natural de feridas, sendo mesmo induzida pelos médicos. O recurso a purgas, sangrias, enemas e ventosas era prática médica usual, visando restabelecer o equilíbrio dos humores galênicos; representavam parte significativa do repertório disponível ao médico comum.

Paracelso despertava reações muito fortes. Chamava a atenção já por seu aspecto físico de estatura baixa (em torno de 1,5 m), franzino e imberbe. Sua voz era aguda e ele apresentava envelhecimento precoce. Por muito tempo, tinha constantemente consigo uma espada quase da mesma altura que ele próprio, presente de um carrasco (RADL, 1913, p. 85; DOOLAN, 2004, p. 22). Incorporou-se à própria iconografia de Paracelso. Também por 
sua personalidade, não passava despercebido: impulsiva, irascível e confrontadora, acarretou-lhe numerosos contratempos e dissabores.

Talvez por estar constantemente às voltas com críticas, ataques, censura e mesmo forçado à fuga para escapar do encarceramento, não foi possível a Paracelso deixar à posteridade a sua visão dos eventos. À parte documentos elaborados mais tardiamente por seguidores seus, sobrevivem quase exclusivamente os registros de seus adversários e detratores, empenhados em denegri-lo. Acabaram por construir a imagem negativa ainda hoje associada a seu nome: alquimista, místico, charlatão curandeiro, maluco. Dentre outras coisas, foi acusado de corromper a juventude, difamar toda a categoria médica, de ser apenas um ébrio e só saber tratar sífilis.

\section{Por que se ocupar de Paracelso?}

Dentre os aspectos que tornam Paracelso objeto relevante para uma reflexão sobre a história das ciências e o papel que nela desempenha a tradução (tema aglutinador do presente volume), destaquemos, por um lado, sua condição de precursor de várias áreas de conhecimento modernas. $\mathrm{O}$ tratado traduzido, Von den ersten drei Essentiis, apresenta vínculos com a Medicina e a Química, caracterizados de forma breve a seguir. Por outro lado, questões diretamente vinculadas à linguística e à tradução também despertam atenção e são contempladas na análise em curso.

\section{Von den ersten drei Essentiis e a Medicina}

$\mathrm{O}$ vínculo com a Medicina se dá pela contraposição direta à doutrina dos quatro humores hipocrático-galênicos (bile amarela, bile negra, flegma e sangue) - hegemônica, se não praticamente consensual no campo da ciência, à época. No lugar dos "humores" intangíveis, indefiníveis e misteriosos de Hipócrates, Paracelso propôs "essências" com características de materialidade. Defendia firmemente a importância da observação e do trabalho empírico, postura similar àquela vigente nos trabalhos dos alquimistas.

A atuação de Paracelso certamente contribuiu para que a observação empírica, tão cara aos alquimistas, fosse valorizada também em outras áreas de estudo - que até então se orientavam sobretudo pela teoria recebida, sem 
procurar convalidá-la via prática, à qual era dado um estatuto inferior, derivado, de mera aplicação de princípios científicos como fundamentação teórica que norteia a tomada de decisões práticas. Em outras palavras: a empiria não estava autorizada a contestar o conhecimento teórico já estabelecido, de modo que quaisquer mudanças na teoria, na medida do concebível, teriam de derivar da própria reflexão teórica, dispensando a necessidade de convalidação experimental/empírica, fundamental no paradigma contemporâneo das ciências da natureza. Essa nova postura em relação à observação e experimentação empírica foi importante para a evolução de diversas áreas do conhecimento e o próprio surgimento da mentalidade científica moderna ainda que sua consolidação só tenha ocorrido bem mais tarde.

\section{Von den ersten drei Essentiis e a Química}

O vínculo do tratado em questão com a Química é menos evidente. Nele, Paracelso recorre ao chamado tria prima, composto por sulphur, mercurius e sal, trazido de sua bagagem alquímica. A Alquimia tradicionalmente considerava a matéria como sendo composta por sulphur e mercurius filosofais. Paracelso expandiu esse modelo, ao incluir sal. ${ }^{2} \mathrm{O}$ conjunto tria prima serviu de base, provavelmente pela presença do sulphur (enxofre filosofal), combustível, para o surgimento da teoria do flogisto (e das práticas nele baseadas), que buscava(m) explicar fenômenos de variação de massa, então imprevisíveis e inexplicáveis, em exposição de matéria a fogo. A teoria do flogisto foi derrubada apenas pelos trabalhos de Lavoisier dois séculos mais tarde, como registra Thomas Kuhn (1973, p. 98-142) em sua obra seminal A estrutura das revoluções científicas, usando o caso para ilustrar seu argumento de crise da ciência:

Quando, a partir de 1770, Lavoisier iniciou suas experiências com o ar, havia tantas versões da teoria do flogisto como químicos pneumáticos. Essa proliferação de versões de uma teoria é um sintoma muito usual de crise. Em seu prefácio, Copérnico queixou-se disso.

\footnotetext{
2 Note-se que o conceito de sal por detrás do termo usado por Paracelso diverge de sua acepção hoje corrente, seja na ciência ou no uso cotidiano, motivo pelo qual recorremos ao destaque em itálico - nesse e em outros casos semelhantes.
} 


\begin{abstract}
Contudo, a crescente indeterminação e a utilidade decrescente da teoria flogística não foram as únicas causas da crise com a qual Lavoisier se defrontou [a nota 8 no texto remete ao "material relevante disperso na obra de J. R. Partignton e Douglas MecKie, 'Historical Studies on Phlogiston Theory', Annals of Science II, 1937"]. (KUHN, 2006, p. 98-99) ${ }^{3}$
\end{abstract}

\title{
Mudança de paradigma e condições transcendentais
}

Não surpreende que Kuhn não mencione Paracelso ao discutir a superação da teoria do flogisto por Lavoisier, dada a distância temporal e tendo em vista o ostracismo a que fora relegado Paracelso. Para dar conta de como a mudança de perspectiva introduzida por Paracelso foi vital para o estabelecimento da teoria do flogisto e, com isso, do paradigma científico que a substituiu, cabe recorrer a um brevíssimo recorte da vasta e densa obra do epistemólogo francês Gilles Gaston Granger. Na discussão das condições de possibilidade do conhecimento científico, através das noções de "categoria" - do pensamento, à maneira de Kant - e "categoria derivada" (regiões do saber), Granger (1994, p. 55-57 [capítulo 3, seções 1.2 e 2.1]) propõe que o "princípio da dualidade" é a "regra constitutiva de todo pensamento do objeto", ao passo que as diferentes regiões do fazer científico abrigam diversas "categorias derivadas" que, uma vez "estabelecida de facto a relação das operações aos objetos que caracterizam o conhecimento científico positivo", submetemse a mutações que deslocam os limites dos respectivos domínios ao longo do tempo:

Uma vez conquistados, dentro de um domínio, o uso e a exploração da categoria da dualidade, a história - por assim dizer - transcendental desse domínio passa a se confundir com a de suas categorias derivadas. (GRANGER, 1994, p. 57; tradução nossa)

\footnotetext{
${ }^{3}$ Nossa aplicação da noção kuhniana de paradigma ao modelo vigente na época de Paracelso, como o sistema dos quatro humores, ou à posterior teoria do flogisto, é certamente mais frouxa do que permitiria o debate especializado. No entanto, entendemos ser legítimo esse uso retrospectivo - e alargado - do conceito para incorporar à discussão o aspecto das práticas vinculadas aos respectivos modelos teóricos. O conceito de paradigma de Kuhn pressupõe referencial teórico comum e práticas largamente compartilhadas, motivo pelo qual dificilmente poder-se-ia falar de paradigma se "havia tantas versões da teoria do flogisto quanto químicos pneumáticos" (ibid.). O mesmo se aplica ao caso de Paracelso. E, no entanto, dificilmente poderíamos passar hoje ao largo do conceito de Kuhn, ao tratar desse assunto - não havendo aqui, por outro lado, necessidade de se discutir em profundidade até que ponto poder-se-ia falar de paradigma em cada um desses casos (cf. nota 4 , abaixo).
} 
Trata-se aqui de uma reflexão explicitamente tributária da filosofia transcendental kantiana, cujo objetivo é, como observado de passagem acima, investigar as "condições de possibilidade" do pensamento. ${ }^{4}$ Andy Hamilton (2014) sintetiza bem esse espírito, em sua apresentação didática de Da Certeza, último escrito de Wittgenstein (2004 [1969]). Hamilton (2014, p. 291) explica: “Argumentos transcendentais afirmam que $X$ é uma condição necessária para a possibilidade de $\mathrm{Y}$ - e que, sendo o caso de $\mathrm{Y}$, então também é o de $X^{\prime \prime}$. No argumento de $D a$ Certeza contra o cético, isso se expressa da seguinte forma: para que possa duvidar de algo, o cético tem antes de pressupor algum tipo de conhecimento e, nesse sentido, as ideias de conhecimento e certeza são logicamente anteriores à da dúvida. Daí a não-pertinência da dúvida cética radical. Outros exemplos que venhamos a agregar teriam a mesma forma, como nos casos a seguir: para que se possa contar, é preciso antes ter a noção de unidade, e de seu desdobramento em números; para que se possa medir ou pesar, são necessárias unidades e escalas - de pesos e medidas - etc.

Lavoisier superou os modelos e as práticas vinculadas à teoria do flogisto, que já operavam no domínio do empírico, mas o paradigma daí resultante manteve a empiria como critério norteador. Os contemporâneos de Paracelso ainda não reconheciam esse domínio como de relevância científica. Nesse sentido, foi a valorização do empírico operada por Paracelso - conforme registrado nas seções 2.1 e 2.2 - que preparou o terreno para o paradigma derivado da teoria do flogisto, e o de outras ciências empíricas no

\footnotetext{
4 Ver também Granger (1990). Arley Moreno (2005 [Introdução, Cap. I]) discute as nuanças do conceito de "transcendental" a partir de Kant e seu uso por Granger, levando em conta também outros filósofos cujas obras impactaram a ciência, como Husserl e Frege - a despeito das claras diferenças entre esses dois domínios. Terá razão quem sugerir que a questão deixa-se também abordar por outras vias, com destaque para os "herdeiros de Kuhn". Uma tal abordagem estará mais próxima da discussão contemporânea nos Estudos da Tradução e merece certamente ser considerada em desdobramentos futuros da presente pesquisa. Mas quando se trata de enfatizar a importância da valorização da empiria como condição de possibilidade para o que veio depois, o argumento transcendental é imbatível, e pode ajudar a mostrar elos de ligação não percebidos na atual compartimentalização excessiva do fazer científico. Essa é uma das tarefas que se coloca a "epistemologia do traduzir" (OLIVEIRA, 2019). Aqui, tem-se uma interface com a filosofia da linguagem, e não com a teoria da ciência - sem prejuízo de ambas. De resto, o foco no argumento transcendental elimina a necessidade de discutir se, e até que ponto, já estaria caracterizado um paradigma científico, no sentido estrito de Kuhn, quando da atuação de Paracelso e mesmo no caso da teoria do flogisto. É por isso que o termo "paradigma" só é vinculado, neste trabalho, ao que ocorreu após os trabalhos de Lavoisier.
} 
sentido contemporâneo, a química de Lavoisier aí inclusa. Adicionalmente às influências diretas já reconhecidas pela pesquisa histórica, através de autores como Marx (1941) e Webster (1995), referidos na seção 1, isso também nos dá uma boa ideia da relevância do resgate de Paracelso para a história transcendental - das ciências, para o qual a adoção de estratégias tradutórias condizentes com a tarefa pode assumir um papel importante.

\section{Questões linguísticas e de tradução}

Um aspecto de grande interesse para o projeto tradutório retratado encontrase no plano linguístico. Paracelso optou por usar o vernáculo de sua época, o Neufrühhochdeutsch, forma inicial do alemão moderno. Isso implicava enfrentar a carência de estruturas linguísticas e a falta de vocabulário refinado, mais especificamente de Terminologia, dentre outras dificuldades inerentes a uma língua nascente. Para lidar com tais limitações, Paracelso lançou mão de recursos como empréstimos (especialmente do latim) e neologismos.

Um ponto de interesse adicional para investigar e traduzir o(s) texto(s) de Paracelso reside em sua baixa disponibilidade em português, seja via tradução direta ou indireta. Desse modo, um dos objetivos da pesquisa em curso é propor uma forma adequada para lidar com cenários dessa natureza em situação de tradução.

\section{A questão do escopo}

A análise em curso tem por base três versões do tratado Von den ersten drei Essentiis: a versão inserida na chamada coletânea Huser (VON HOHENHEIM, 1589, p. 15-23), composta de dez volumes publicados entre 1589 e 1591); a versão da chamada edição Sudhoff (VON HOHENHEIM, 1930, p. 1-11), com catorze volumes publicados entre 1922 e 1933; e a versão contida na coletânea feita por Peuckert (VON HOHENHEIM, 2010, p. 322332): cinco volumes, com publicação original em 1965 e republicação em 2010.

No cotejo dessas três versões, observam-se diversos pontos em comum e de diferenciação. A primeira constatação diz respeito à diferença dos objetivos a que tais versões se propõem. Enquanto a versão Huser se dirige 
a um público especializado, i.e., aos médicos de sua época, buscando apresentar e divulgar uma nova visão da teoria das doenças e de como tratá-las, as versões posteriores já não contemplam tal objetivo. Pretendem, isto sim, permitir o acesso dos leitores de suas respectivas épocas a textos de Paracelso, antigos e de disponibilidade restrita - porém não mais como conhecimento científico vigente, e visam alcançar um público mais amplo, i.e., não restrito à área médica.

Um aspecto que aproxima as edições Huser e Sudhoff é o tratamento dos elementos textuais em latim. Para ambas, era razoável presumir que o público-alvo tivesse domínio de latim suficiente para uma compreensão adequada. Outro ponto de aproximação, já à primeira vista, é que ambas versões empregam fontes do grupo chamado Frakturschrift, geralmente chamada de "escrita gótica", ao passo que a versão Peuckert apresenta uso de fonte Antiqua, na "escrita românica". Se no séc. XV o uso da Frakturschrift era o padrão, o conhecimento da Frakturschrift continuou a ser amplamente difundido entre a população alemã até os anos 1920/30, sendo cabível pressuporse seu domínio pelo público geral. Com sua queda em desuso nos anos 1940, tem-se que, nos anos 1960, quando da edição Peuckert, a premissa de seu conhecimento generalizado já não era admissível (cf. Figura 1).

1) Edição Huser

Ecin wircfung iff orenfach: Eine ift ocs Galss/Dic nimpt fin/Durch purgiereiz/liumbificieren/balfanticren/vno Derglcix

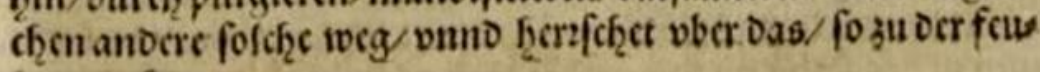
lunts acit.

2) Edição Sudhoff

Bein wirfung ift breifad) : eine ift Des fal3s, bie nimpt bin ourd purgiren, munbificiren, balfamiren unb ber glei. den anber folde weg unb berfdet uber bas fo zu ber feu. lung gebet.

3) Edição Peuckert

Seine Wirkung ist dreifach: eine ist des Salzes, die nimmt hin durch Purgieren, das ist Abführen, Mundificieren, das ist Reinigen, Balsamieren und andere dergleichen Wege, und herrschet über das, so zur Faulung geht. 
Figura 1: O mesmo trecho em três edições distintas

Não é preciso dominar o idioma para perceber ligeiras diferenças formais entre as três edições alemãs, no breve trecho tomado como exemplo para além da questão da fonte usada. Há, por exemplo, vírgulas para separar termos de uma enumeração na segunda (Sudhoff), sendo que na primeira (Huser) toda segmentação é feita através de barras ("/"), à exceção dos sinais de dois pontos e ponto final. A terceira (Peuckert) dá continuidade a essas nuanças de formalização, agregando vírgulas também para separar orações - o que na primeira também se dava por barras e na segunda simplesmente foi omitido. Tratam-se aqui de marcas do longo e vagaroso processo de formalização da linguagem escrita, o que certamente não é o objeto de nossa análise, mas já mostra que o "mesmo" texto, até em sua (re-)apresentação formal, adequa-se ao contexto de sua produção.

A versão Peuckert se diferencia também por outro prisma, certamente mais relevante para nossa discussão: há evidências de preocupação do autor com a compreensão pelo leitor, tanto de certos aspectos do próprio alemão que sofreram alterações ao longo do tempo quanto dos elementos latinos inseridos por Paracelso (que recebem tradução ou paráfrase explicativa). Peuckert demonstra ter consciência de que não seria razoável presumir que seu leitor tivesse os conhecimentos de latim do público-alvo de Sudhoff ou Huser, uma vez que os conhecimentos de latim, bastante difundidos ainda no início do século, ficaram mais restritos nos anos 1960. Diante do exposto, é razoável considerar-se que cada uma das versões tratadas tenha um propósito - ou escopo - específico.

Aqui, cabe um breve excurso para retomar um aspecto do conceito de "escopo" pouco ou nada discutido nos Estudos da Tradução correntes, a saber, sua fundamentação hermenêutica de longa data, enquanto elemento central para a teoria da interpretação, antes mesmo da fundamentação mais geral de uma hermenêutica propriamente filosófica - aplicável a qualquer tipo de texto - como proposta por Schleiermacher no século XIX. Em sua síntese do percurso das hermenêuticas particulares (jurídica, teológica etc.) à hermenêutica geral (filosófica), Paulo Cesar Duque-Estrada (2010) aponta para o papel do "escopo" já em autores como Spinoza e Claudenius, que 
atribuíam à interpretação um caráter apenas ocasional, perspectiva posteriormente superada pela contribuição de Schleiermacher, para quem toda compreensão traz em seu bojo elementos de não-compreensão, não sendo possível separar nitidamente compreensão e interpretação. Registra Duque-Estrada que

tanto em Spinoza quanto em Claudenius, sempre que um procedimento interpretativo se fizesse necessário, ele deveria se orientar por um antigo princípio hermenêutico, o princípio universal da interpretação textual, já conhecido pela tradição retórica clássica e incorporado por Lutero e seus sucessores. Segundo tal princípio, "todos os detalhes de um texto devem ser compreendidos a partir do contextus, do conjunto, bem como do sentido unitário para o qual o todo [do texto] está orientado, o scopus." (DUQUEESTRADA, 2010, p. 51; destaques e observação entre chaves são do autor; a citação remete a H-G. Gadamer em Verdade e Método) ${ }^{5}$

Retomando o que foi dito acima na seção 2.3, pode-se então perceber que a noção hermenêutica de "escopo" recebida da tradição faz parte da história transcendental de sua aplicação contemporânea ao fenômeno da tradução (a Skopostheorie de Hans Vermeer e Katharina Reiss), na qual se argumentará que textos traduzidos podem, sim, ter escopo igual ou semelhante ao do texto original, mas que esse não é o único caso possível, sendo a variação de escopo uma possibilidade reconhecida como plenamente válida e, num certo sentido, absolutamente natural. Tal constatação permite encerrarmos esse breve excurso sobre a natureza da interpretação, retomando o fio da meada de nossos dados empíricos, com a constatação de que há variação no escopo das edições diferentes edições do texto de Paracelso na Alemanha - e que tal possibilidade de variação se aplica a fortiori também aos casos de tradução desses textos.

Ao passo que a versão Huser mira a divulgação de um modelo científico entre pares, contemporâneos, a versão Sudhoff busca permitir acesso a

\footnotetext{
${ }^{5} \mathrm{O}$ argumento continua, mais adiante: “Tal princípio, como já dito, era observado apenas ocasionalmente, quando o encontro com alguma passagem obscura comprometia a compreensão de um texto. Schleiermacher, por sua vez, e por contraste, passa não mais a perceber a situação de um mal-entendido, ou seja, de uma interrupção do fluxo da compreensão, como uma situação ocasional, esporádica. Ao contrário, o mal-entendido, segundo ele, constitui uma experiência humana universal. Não que a compreensão, para ele, seja impossível, mas sim que 'a experiência do que é estranho' e a possibilidade do mal entendido é universal'” (DUQUE-ESTRADA, 2010, p. 51-52; aqui também, o trecho citado pelo autor remete a H-G. Gadamer em Verdade e Método).
} 
um texto já antigo, naquele momento, a um público relativamente familiarizado com o Neufrühochdeutsch, com domínio da leitura de Frakturschrift e conhecimento de latim. A versão Peuckert, por sua vez, destina-se a falantes do alemão moderno, sem pressupor familiaridade nem com o Neufrühochdeutsch nem com o latim, nem tampouco domínio da leitura de Frakturschrift. O escopo proposto para a tradução brasileira emula em boa medida aquele da versão Peuckert, acrescentando um aspecto importante: a passagem do texto para o português. Ou seja, busca-se um texto de chegada que permita o acesso de falantes de português ao texto de Paracelso, porém sem lhe franquear todas as portas, remover todas as dificuldades - tal como fez Peuckert em relação ao público germanófono. Um dos objetivos dessa escolha deliberada é induzir algum nível de estranhamento, ao confrontar o leitor com certas dificuldades de leitura. Sua função é servir de lembrete de que estamos lidando com um texto de aproximadamente 500 anos, elaborado em um ambiente cultural significativamente diferente daquele que nos é familiar. Trata-se, portanto, de uma estratégia de desnaturalização, na direção oposta ao ideal de "fluência" e "transparência" propugnado pela tradição. Isso porque, num certo sentido, uma apreensão de textos históricos sem consciência do gap que deles nos separa trará necessariamente em seu bojo uma boa dose de inadequação - mais ainda quando o que está em jogo é também apontar para diferenças significativas entre o pensamento contemporâneo e o daquela época, ao mesmo tempo em que se traça uma linha de continuidade entre eles.

\section{Teoria do escopo (Skopostheorie) nos Estudos da Tradução}

Se o entendimento adequado de um texto passa pela consideração do escopo de sua escrita, como já preconizava a retórica clássica, tornando-se esse um princípio hermenêutico geral, conforme argumentado na seção anterior, a leitura de textos distantes no tempo impõe um olhar que é, num certo sentido, retrospectivo, ao procurar dar conta de tal exigência. Por outro lado, ao se reimprimir um texto numa nova edição com distância temporal, há de se levar em conta também o contexto - ou horizonte - de sua recepção, posto que o público leitor da reedição é, por definição, diferente daquele da edição original, mesmo quando as mudanças mais significativas decorrerem mais 
da passagem do tempo do que de fatores de outra ordem. É isso o que fazem tanto a edição Sudhoff como a Peuckert, conforme ilustrado através de alguns elementos acima. Com isso, as novas edições procuram fornecer elementos que facilitem a "fusão de horizontes", tal como entendida por HansGeorg Gadamer (na esteira de Schleiermacher):

\footnotetext{
[...] na compreensão não se trata de uma "compreensão histórica" [ou "genética", no linguajar contemporâneo], que reconstrói as etapas de produção do texto. Isso significa que os próprios pensamentos do intérprete estão sempre inseridos no processo de reavivar o sentido do texto. Destarte, o horizonte do intérprete é determinante, mas não como um ponto de vista pessoal que se mantém ou se impõe, mas antes como uma opinião e uma possibilidade que entram em jogo e que ajudam a incorporar o que verdadeiramente está dito no texto. A esse processo chamamos fusão de horizontes. (GADAMER, 2010, p. 245, 247 [páginas ímpares em português])
}

Ora, a tradução de um texto introduz mudanças no contexto (ou horizonte) de recepção que vão muito além - ou são de natureza diversa - daquelas decorrentes sobretudo da passagem do tempo. Nesse sentido, não surpreende que o conceito de "escopo" tenha chegado ao campo da teoria da tradução. No caso do presente trabalho, no qual se aceita plenamente a ideia de que o propósito de um texto - seu escopo - é um bom guia na procura por uma compreensão adequada, é um passo natural adotar a Skopostheorie desenvolvida na Alemanha como fundamentação teórica que norteará a tomada das várias decisões práticas - e coerentes entre si - que se fazem necessárias em diversos níveis, ao longo do processo tradutório (cf. LEVÝ, 2004 [1967]; REISS, 2004 [1971]; TIRKKONNEN-CONDIT, 1993; NORD, 2005).

Não cabe aqui uma discussão mais aprofundada desse referencial teórico, mas, levando em conta que, no Brasil, ele não é moeda corrente fora dos departamentos de alemão (ainda que não se seja totalmente desconhecido nos círculos dos Estudos da Tradução), apresenta-se a seguir uma síntese de seus aspectos mais relevantes para o presente trabalho. Tampouco se pretende que todos elementos dessa síntese possam ser ilustrados pelos exemplos fornecidos mais abaixo. Trata-se antes de esboçar o pano de fundo diante do qual foram selecionados os aspectos considerados relevantes e tomadas as decisões norteadoras da tradução. 
A Skopostheorie foi apresentada inicialmente por Hans Vermeer (1978) e refinada, em texto posterior, por Katharina Reiss e o próprio Hans Vermeer (1984). A teoria se pauta por algumas regras, hierarquicamente encadeadas, que apresentamos abaixo (REISS; VERMEER, 1984, p. 119):

1) Uma tradução é condicionada pelo escopo. Escopo é o propósito de uma tradução. Pode diferir daquele do texto-fonte, podendo até ser específico para partes diferentes do texto. Ele precisa fazer sentido e ser justificável na cultura de chegada.

2) Uma tradução é uma oferta [Angebot], no âmbito de uma cultura e língua de chegada, sobre uma oferta de informações [Informationsangebot] em uma cultura e língua de partida. A oferta apresentada pela tradução não é biunívuca.

Tradução envolve recepção de texto. Primeiro, do texto-fonte pelo translator, depois, do texto de chegada pelo leitor, sempre condicionadas pela bagagem cultural do respectivo receptor. Por este encadeamento de recepções, uma tradução deve ser encarada como um conjunto de informações sobre as informações lidas no texto-fonte.

3) Uma tradução precisa ser internamente coerente.

$\mathrm{Na}$ cultura de chegada, o leitor deve ser capaz de interpretar o texto recebido sem maiores estranhamentos, salvo se estranhamento for parte constitutiva do escopo proposto.

4) A tradução precisa ser coerente [i.e. condizente] com o textofonte.

Condicionado pelo escopo adotado, o texto de chegada precisa manter coerência com:

- o conteúdo presente no texto-fonte;

- a interpretação do texto-fonte feita pelo tradutor;

- as intervenções do tradutor, visto como coautor do texto de chegada. ${ }^{6}$

\footnotetext{
${ }^{6}$ Do ponto de vista epistêmico, e conforme a breve síntese hermenêutica apresentada acima, os três tópicos arrolados neste ponto (4) são variações do mesmo tema, na medida em que não há como separar assepticamente o que está contido no texto, é a interpretação do tradutor e/ou sua interferência no texto. A esse respeito, vide conceito de aplicação de H-G. Gadamer (1993 [1968], p.108-110).
} 
Ou seja, uma tradução bem-sucedida permite ao receptor uma interpretação coerente e sem maiores dificuldades, resguardada a possibilidade de algum grau de estranhamento fazer parte do próprio escopo.

No mais, segundo esse referencial, que a partir de certo momento passou a ser conhecido como abordagem funcionalista (termo que engloba a produção de outr*s teóric ${ }^{*}$ s que deram continuidade à teoria do escopo de Vermeer \& Reiss), um texto, como ato de fala, é condicionado pelo contexto de sua realização, já que o seu autor é inevitavelmente influenciado pelo ambiente (cultural) em que está. Os mesmos tipos de diferenças que se verificam entre línguas distintas entre si ocorrem, ainda que de forma mais limitada, até mesmo no encontro entre formas variantes de uma mesma língua (KAPUŚCIŃSKA, 2011, p. 215). Por esse prisma, o autor de um texto, cuja percepção de mundo se vincula à sua cultura, ainda que inconscientemente, a reflete ao produzir o seu texto, manifestando os condicionamentos impostos pelas circunstâncias de elaboração do texto como, por exemplo, o ambiente cultural, o momento histórico e o local, defende Christiane Nord (2016, p. 43,$45 ; 2000)^{7}$ - cuja reflexão se encontra no cerne da abordagem tradutória adotada na pesquisa em curso.

Argumenta também essa autora que no encontro entre duas línguas, culturas ou momentos históricos podem se manifestar as chamadas diferenças culturais (NORD, 2005, p. 869), constituindo dessa forma uma “barreira cultural" que dificulta ou mesmo impede que o volume de elementos em comum seja o suficiente para permitir uma comunicação efetiva. Nessa situação, caberia à tradução estabelecer as pontes necessárias (NORD, 2016, p. 43). Na mesma linha, a teoria em tela sugere que a "barreira cultural" pode

\footnotetext{
${ }^{7}$ Note-se aqui a linha de continuidade com a ideia de fusão de horizontes proposta por Gadamer. Isso não significa que a teoria do escopo seja uma continuidade imediata da tradição hermenêutica, mais ainda porque combate certos preceitos valorizados em algumas vertentes da hermenêutica, como a noção de invariância (Invarianz). O problema com a demarcação muito rígida entre abordagens que entram em competição é o risco de apagamento de elementos que as aproximam. Um caso raro de estudo comparativo é a discussão feita por Dilek Dizdar (2006), que transita entre a desconstrução derridiana e o funcionalismo de Vermeer, levando em conta também os estudos descritivos na linha de Gideon Toury (cf. OLIVEIRA, 2019; ver também STERVID, s.d).
} 
gerar de ruídos a conflitos na comunicação, posto que a eficiência da compreensão depende, dentre outros, da bagagem cultural e das expectativas do/a receptor(a) (NORD, 2002, p. 36). Caberia então ao/à tradutor(a) atentar para potenciais pontos de conflito e, atendendo ao escopo da tradução, tomar as decisões tradutórias necessárias para alcançar o objetivo proposto (NORD, 2005, p. 870).

A abordagem funcionalista permite relevante liberdade de ação a quem traduz, com o objetivo de facilitar a recepção - no sentido da adequação contextual, e não de uma redução simplificadora, está claro. Contudo, há limites. Antes de mais nada, assumir a centralidade do escopo implica que quem traduz precisa respeitar o escopo definido. Segundo Alice Leal (2016, p. 3), também é necessário considerar fatores extratextuais - analisáveis antes da leitura - relacionados às circunstâncias de elaboração e uso do textofonte (autor*, receptor* visad*, meio de comunicação usado, momento e local de elaboração), assim como aspectos intratextuais, referentes a características do texto e relacionados a itens como léxico, estrutura frasal e estilo.

Outra limitação imposta a quem traduz, conforme Nord (2002), é a vinculação da tradução ao contexto do contato intercultural entre duas culturas específicas. Por este raciocínio, quem traduz deve ser responsável ao fazer a intermediação entre os dois lados, buscando antever e prevenir malentendidos e conflitos (NORD, 2002, p. 36). Defende a autora que o perfil do escopo da tradução deve se moldar às especificidades de cada público-alvo visado (NORD, 2000, p. 1). Assim, fica claro que escapa ao controle de quem traduz o êxito efetivo da tradução, para o qual contribuirá - ou não - uma miríade de fatores, sejam circunstanciais ou mais diretamente ligados às disposições receptivas do público leitor/receptor.

\section{Da tomada de decisões na tradução de Von den ersten drei Essentiis}

O tratado Von den ersten drei Essentiis apresenta alguns pontos de interesse quanto à sua tradução. Nele se verifica uma curiosa superposição de características. Trata-se de um texto elaborado há muito tempo e usando uma forma precoce do alemão moderno, no que pode ser tomado como forma de 
autoafirmação de uma língua em formação. ${ }^{8}$ No outro extremo, observa-se presença abundante de empréstimos do latim. Entre esses extremos, tem-se a presença de palavras latinas em estágios variados de assimilação ao alemão. Cada parte desse mosaico está associada com desafios específicos a quem traduz. De modo esquemático, tais desafios podem ser aglutinados em alguns grupos principais, apresentados a seguir.

\section{Alterações semânticas no alemão}

Já transcorreram quinhentos anos desde a elaboração de Von den ersten drei Essentiis, e nesse período ocorreram alterações no alemão, decorrentes da própria evolução do Frühneuhochdeutsch, em que foi elaborado, para o atual Neuhochdeutsch.

Um exemplo simples já dá conta de ilustrar essa evolução como marca clara no campo semântico. Em todas as versões do tratado consideradas encontra-se "Andere Kapitel" como título do segundo capítulo. Ora, no alemão moderno, "andere" tem como significado principal "outro", ao passo que na época de Paracelso ainda guardava proximidade com aquele presente, ainda hoje, em línguas nórdicas, como o sueco, onde tem significado duplo: "outro", além de "segundo" (numeral ordinal). Em casos assim, a manutenção da marca histórica ou a opção por formulação mais transparente/contemporânea dependerá, em grande medida, do grau de estranhamento que o escopo da tradução admitir para o trecho em questão.

\section{A presença de elementos latinos em Von den ersten drei Essentiis}

No texto do tratado, é facilmente perceptível a abundante presença de elementos latinos, o que levanta, por si só, um conjunto de questões a serem levadas em conta na tradução. Destacamos a seguir os aspectos mais evidentes, que exigem a tomada de decisões que levem a critérios passíveis de um

\footnotetext{
${ }^{8}$ André Lefevere \& Susan Bassnett (1992, p. 8), em coletânea seminal para a virada cultural, relatam atitudes semelhantes - via tradução. Uma delas seria a de Julius Nyerere que, ao traduzir Shakespeare para o Swahili, quis demonstrar que a língua de seu país é capaz de expressar o que é dito numa língua de prestígio. Outro exemplo seria a "clonagem" do repertório cultural alemão para a língua tcheca no século XIX.
} 
nível razoável de generalização, e agregamos alguns exemplos à guisa de ilustração.

\section{Como tratar a declinação?}

O alemão, ao contrário, do português, compartilha com o latim o uso de declinações (marcação morfológica da função sintática exercida por um sintagma). No texto de Paracelso, observa-se a plena integração dos elementos latinos no texto alemão, incluindo a declinação, a ponto de ser possível substituição palavra por palavra. Tendo em vista o desconhecimento quase completo de latim - em especial de suas características sintáticas - pelo leitor lusófono atual, decidiu-se, no texto de chegada, deixar de lado a presença de elementos morfológicos indicativos da declinação, em analogia ao que se verifica no português. O objetivo foi evitar passar ao leitor uma impressão distorcida quanto ao volume de palavras latinas. Quanto a elementos latinos na forma de agrupamentos de palavras, a declinação foi mantida inalterada. Deste modo, "Innere des corporis" foi traduzido por "interior do corpus", enquanto "in salem" foi mantido inalterado.

\section{O que traduzir?}

O escopo da proposta textual apresentada por Peuckert visava leitores germanófonos e, tendo isso em vista, agregou-se a certos elementos latinos uma tradução ou paráfrase explicativa, selecionando-se, para tanto, aqueles de compreensão mais difícil para falantes de alemão. Embora a proposta da tradução para o português seja emular o escopo da versão de Peuckert, o público-alvo considerado é distinto, lusófono. Coerentemente, a seleção dos elementos a serem explicados levou em conta as potenciais dificuldades desse novo público - e não a do público germanófono de Peuckert. Afinal, "cerebro", por exemplo, é talvez indecifrável para germanófonos, mas perfeitamente compreensível a lusófonos.

O cotejo abaixo, de um mesmo trecho das duas versões, com as intervenções explicativas sublinhadas, ilustra bem a situação: 
Wie nun aus dem archeo das Salz laxativischer Art geht, - eins purgiert stomachum, denn es kommt aus dem stomacho archei, eins purgiert die Milz, denn es kommt aus der Milz archei, und so auch mit cerebro, das ist Gehirn, iecore, das ist die Leber, pulmone, die Lunge, und mit anderen, - so ursacht das membrum archei das membrum oder Glied microcosmi.

(Von HOHENHEIM, 2010, p. 324-325)
Agora, como o sal de tipo laxativo provém do archeus - um [sal] purga o stomacho, pois provém do archeus do stomacho, um [sal] purga o baço, pois provém do archeus do baço e assim também com o cerebro, iecore (年́ado), pulmone e com outros - assim o membrum do archeus origina o membrum do microcosmos.

(WAGNER, 2019 [em andamento])

Complementando e reforçando o que foi dito acima, note-se que nem todas as intervenções explicativas de Peuckert foram incorporadas à tradução para o português que, por sua vez, agrega novos recursos explicativos, direcionados ao público lusófono. Trata-se de variações contextuais destinadas a permitir uma compreensão adequada ao contexto e ao escopo de cada edição/tradução, constituindo dessa forma o texto de Paracelso em suas inúmeras leituras, no sentido propugnado por Kanavillil Rajagopalan, em autocitação (2013, p. 106):

uma leitura de um texto é uma extensão do próprio texto. Isto é, nenhum texto segue "inafetado" pelas suas sucessivas leituras. Cada nova leitura acrescenta algo a esse texto [qu]e é completamente incorporado ao "significado" do texto, [de modo que] o significado do texto - na medida em que algo assim existir - pode ser descrito como aquilo que está sofrendo constantes mudanças, apesar da sensação ilusória de que seja o mesmo e idêntico objeto com o qual se está lidando em ocasiões sucessivas. ${ }^{9}$

\footnotetext{
${ }^{9}$ Estamos aqui no polo oposto da visão positivista como "teoria invisível" que propugna um tertius comparationis fixo, imutável e independente $\mathrm{d}^{*}$ leitor* e seu contexto de recepção, no sentido do registro feito por Bassnet \& Lefevere (1992, p. 3): “apesar de muit*s d*s linguistas que escrevem sobre a tradução estarem familiarizad*s com a obra de Karl Popper, Thomas Kuhn e outr*s teóric*s da ciência, o positivismo ainda opera nas sombras como a 'teoria invisível' [...] por trás do que *s mesms linguistas escrevem sobre o tópico". Nosso uso de * para indicar variação de gênero, mesmo ao traduzir, ilustra o raciocínio de Rajagopalan. As intervenções que fizemos em sua autocitação, traduzida do inglês, vão no mesmo sentido: "de modo que" como tradução de "so that", por exemplo.
} 


\section{Germanizações em Von den ersten drei Essentiis}

Além do perfeito entrosamento observado entre os elementos latinos e o texto alemão em que está inserido, também se verifica a ocorrência de palavras latinas mostrando graus variáveis de assimilação pelo alemão. Para cada um desses estágios foi necessária avaliação e decisão tradutória específica.

\section{Formas de germanização que não se incorporaram definitivamente}

Para contornar algumas dificuldades e limitações impostas pelo Neufrühhochdeutsch, Paracelso recorreu a enxerto de palavras e passagens em latim em seu texto. Além disso, também apresentou neologismos, palavras "híbridas". Consideramos aqui como "híbridas" as palavras latinas às quais foram aplicadas as regras linguísticas do alemão como, por exemplo, o uso do sufixo "-ieren" para dar origem a verbos ou do sufixo "-isch" para gerar adjetivos. Palavras desse grupo não foram definitivamente assimiladas e hoje geram estranhamento ao germanófono. Para emular essa situação, foram traduzidas também por neologismos em português. Um caso concreto é o termo "annualisch", que se tornou "anuálico" na tradução para o português.

\section{Formas de germanização com incorporação localizada e limitada}

Como segundo grupo de germanizações encontradas em Von den ersten drei Essentiis, há aquelas que foram incorporadas ao alemão, mas se mantiveram restritas a nichos, como em línguas de especialidade. São palavras que muitas vezes são familiares a lusófonos, porém carregam em alemão um sentido ligeiramente diferente daquele em português. Como exemplos, podemos citar:

- "consumieren"/“konsumieren" x "consumir": em alemão vincula-se a consumismo, diferentemente do português;

- "digerieren" x "digerir": em alemão descreve tratamento químico de amostra sólida com líquidos; em português há, além desta, a denotação de aproveitamento biológico de alimentos num organismo vivo. 
Para emular, ainda que em parte, a dificuldade de compreensão encontrada por germanófonos, optou-se em alguns casos pelo uso de formas arcaizadas. Assim, "coloriert" foi traduzido por "colorado". Aqui, como em outros lugares, poder-se-ia perfeitamente optar por outras alternativas. Mas o efeito dessas alternativas no público leitor, se fosse usado, por exemplo, o termo "colorizado" para verter "coloriert", escaparia ao escopo previsto, de emular certo estranhamento, via formas arcaicas. Eis um exemplo, singelo, de como o escopo da tradução pode afetar as escolhas a serem feitas nesse nível, da simples palavra.

\section{Formas de germanização com ampla incorporação localizada}

Há um outro grupo de palavras, também concentradas em línguas de especialidade, que essencialmente mantêm o sentido do latim. Quando muito, sofreram alterações de grafia, e obtêm entendimento padrão por especialistas da respectiva área, mesmo de culturas diferentes. Nesse grupo tem-se casos como "destillieren" e "extrahieren".

"Extrahieren", aliás, ilustra também um outro aspecto. Algumas palavras desse grupo transcendem a língua de especialidade, encontrando trânsito no uso linguístico geral, ainda que muitas vezes de modo vinculado a registros mais elevados. Isso ocorre de forma mais pronunciada em línguas não-neolatinas, como o alemão. Para essas situações, a palavra portuguesa, de raiz latina, foi simplesmente mantida, não havendo proposta de alternativa para emular os efeitos sobre o leitor germanófono.

\section{Breves considerações finais}

Apesar do caráter intrinsecamente interdisciplinar dos Estudos da Tradução, a área ainda padece sob algumas manifestações da compartimentalização de saberes característica da organização acadêmica contemporânea. Na medida do possível e aconselhável, procuramos em alguns momentos romper essa compartimentação, visando superar barreiras colocadas seja pela divisão departamental ou pela tradição linguística. Em parte, isso foi feito através de referências a diferentes teorias e tradições que nem sempre conseguem ir além do espaço reservado a diferentes disciplinas ou "escolas", mas também via breves excursos ou discussão paralela em nota de rodapé. Esperamos ter 
encontrado o equilíbrio necessário para que o texto seja compreensível para leitores com diferentes horizontes de interesse, sem com isso perder o devido rigor. Maiores aprofundamentos poderão ser objeto de investigação futura, seja em desdobramentos teóricos ou pesquisa empírica sobre o respectivo tema.

\section{Referências}

BASSNETT, Susan; LEFEVERE, André. Introduction: Proust's grandmother and the thousand and one nights. The 'cultural turn' in translation. In: . (Eds.). Translation, history and culture. London \& New York: Pinter Publishers, 1990, p. 1-13.

BERNOULLI, R. Paracelsus - physician, reformer, philosopher, scientist. Experientia, Basiléia, v. 50, p. 334-338, 1994.

DEICHMANN, W. B. et al. What is there that is not poison?: A study of the Third Defense by Paracelsus. Archives of Toxicology, v. 58, p. 207-213, 1986. DIZDAR, Dilek. Translation. Um- und Irrwege. Berlim: Frank \& Timme, 2006.

DOOLAN, Paul. Paracelsus: Basel's Luther of Medicine. Cream Magazine, p. 22, nov. 2004.

DUQUE-ESTRADA, Paulo Cesar. Da problemática do método como problema - hermenêutica e a questão do compreender. Gragoatá, n. 29, p. 49-61, 2010.

GADAMER, Hans-Georg. De: Verdade e método. In: HEIDERMANN, Werner (Org.). Clássicos da teoria da tradução. Volume I Alemão-Português. Florianópolis: PGTE/UFSC, 2010. (2ª ed., revista e ampl.; versão eletrônica disponível em $<$ https://repositorio.ufsc.br/>)

GADAMER, Hans-Georg. Klassische und philosophische Hermeneutik. Hermeneutik II. Wahrheit und Methode II. Ergänzungen. Register. Tübingen: Mohr, 1993, p. 92-117. (Publicação original: 1968)

GRANGER, Gilles-Gaston. O formal e o transcendental na matemática. Estudos Avançados, v.4 n.10, p.151-158. São Paulo Sep./Dec. 1990. (Conferência do mês no IEA/USP, 09/10/1990. DOI: http://dx.doi.org/10.1590/S010340141990000300007)

Formes operations objets. Paris: Vrin, 1994. 
HAMILTON, Andy. Routledge philosophy guidebook to Wittgenstein and 'On certainty'. Cambridge, London \& New York: Routledge, 2014.

KAPUŚCIŃSKA, Anna. Was kostet eine Übersetzung? Zu Vor- und Nachteilen der funktionellen literarischen Translation. Lingua Ac Communitas, v. 24, p. 119-128, 2014.

KUHN, Thomas. A estrutura das revoluções científicas. São Paulo: Perspectiva, 2006. (9ª edição; (C) original em inglês: 1962, 1970)

LEAL, Alice. Funcionalismo e tradução literária: o modelo de Christiane Nord em três contos ingleses contemporâneos. Disponível em:

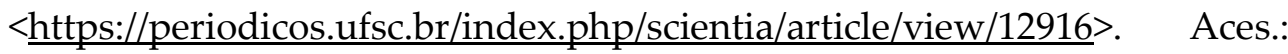
05/10/2016.

LEVÝ, Jiři. Translation as a Decision Process / A Tradução como um Processo de Tomada de Decisão. Scientia Traductionis, n. 11, 2012, p. 72-96. (DOI: http://dx.doi.org/10.5007/1980-4237.2012n11p72. Tradução do inglês: Gustavo Althoff \& Cristiane Vidal. Texto fonte: Translation as a Decision Process, in To Honor Roman Jakobson. The Hague: Mouton, II, 1967, p.11711182, republicado in VENUTI, Lawrence (org.). The Translation studies reader. Nova York: Routledge, 2004, p. 148-159)

MORENO, Arley Ramos. Introdução a uma pragmática filosófica. Campinas: Editora da Unicamp, 2005.

MARX, Hellmut. Die Gestalt des Paracelsus. Klinische Wochenschrift, v. 20, n. 38, p. 958-961, 1941.

NORD, Christiane. What do we know about the target-text receiver? In: BEEBY, Allison et al (Ed.). Investigating translation. Amsterdam: Benjamins Translation Library 32, 2000, p. 1-17.

NORD, Christiane. Manipulation and loyalty in functional translation. Current Writing, v. 14, n. 2, p. 32-44, jan. 2002. Informa UK Limited. (DOI: http://dx.doi.org/10.1080/1013929x.2002.9678123).

NORD, Christiane. Making Otherness Accessible. Functionality and Skopos in the Translation of New Testament Texts. Meta: Journal des traducteurs, v. 50, n. 3, p. 868-880, 2005. Consortium Erudit. (DOI: http://dx.doi.org/10.7202/011602ar).

NORD, Christiane. Defining translation functions. The translation brief as a guideline for the trainee translator. Ilha do Desterro n. 33, p. 39-54, 1997. 
Disponível em:

$<$ https://periodicos.ufsc.br/index.php/desterro/article/down-

load/9208/9484>. Acesso: 01/10/2016.

OLIVEIRA, Paulo. Epistemologia do traduzir: normas de uso e sua descrição a parte post. In LAGES, S.; SARTINGEN, K. (Org.). Traduções e suas vicissitudes. Gragoatá v. 24 n. 49, 2019. (online, no prelo).

RADL, Em. Paracelsus. Eine Skizze seines Lebens. Isis, v. 1, n. 1, p. 62-94, 1913.

RAJAGOPALAN, Kanavillil. Políticas do pós-colonialismo e lutas de poder: sobre os ocasionais e muito conhecidos ataques do revisionismo nos estudos da tradução. In BLUME, Rosvitha Friesen; PETERLE, Patricia (Orgs.). Tradução e relações de poder, p. 95-114. Florianópolis: PGTE/UFSC, 2013. (Versão eletrônica disponível em $<\underline{\text { https://repositorio.ufsc.br/ }>\text { ) }}$

REISS, Katharina; VERMEER, Hans J.. Grundlegung einer allgemeinen Translationstheorie. Tübingen: Max Niemeyer Verlag, 1984.

REISS, Katharina. In: VENUTI, Lawrence (Org.). The translation studies reader. Nova York: Routledge, 2004, p. 160-171. (Publicação original: 1971) STERVID, Beatriz. Do texto ao contexto: uma análise comparativa das abordagens descritiva e funcional dos Estudos da Tradução. s.d (No prelo: aceito para publicação na revista Pandaemonium Germanicum (on line). Previsão: 2020).

STILLMAN, J. M. The Contributions of Paracelsus to Medical Science and Practice. The Monist, v. 27, n. 3, p. 390-402, jul. 1917.

TIRKKONNEN-CONDIT, Sonja. Choice in Translation: A Challenge to Theory and Practice. In: TIRKKONEN-CONDIT, Sonja; LAFFLING, John. (Orgs.). Recent tends in empirical translation research. Joensuu: University of Joensuu, Faculty of Arts, 1993, p. 5-9.

VERMEER, Hans J. Ein Rahmen für eine allgemeine Translationstheorie. Lebende Sprachen, v. 23, n. 3, p. 99-102, 1978. Berlim: de Gruyter. (DOI: http://dx.doi.org/10.1515/les.1978.23.3.99).

VON HOHENHEIM, Philip Theophrast Bombast. Von den ersten dreyen Essentiis, daraus componirt wirt das Generatum. In: HUSER, Johannes (Ed.). Dritter Theil Der Bücher und Schrifften, des Edlen, Hochgelehrten und Bewehrten Philosophi unnd Medici, Philippi Theophrasti Bombast von 
Hohenheim. Basel: Waldkirch, 1589. p. 15-23. Disponível em: <urn:nbn:de:bvb:12-bsb00022504-2>. Acesso em: 04/05/2016.

VON HOHENHEIM, Theophrast. Von den ersten drei Prinzipiis oder Essentiis. In: SUDHOFF, Karl (Ed.). Theophrast von Hohenheim gen. Paracelsus Sämtliche Werke; Abt. 1: Medizinische, naturwissenschaftliche und philosophische Schriften Band 3: Drei Prinzipien, Spiritus vitae, Mineralien, Cemente, Gradationen, Archidoxen und Zugehöriges, Vita longa, Praeparationes, Brief an Erasmus, Macerscholien, Krankheitstypen usw. : aus den Jahren 1526 und Anfang 1527; Erasmusbrief auf Falttafel in Faksimile. München [u.a.] 1930. München/Berlin: Oldenbourg, 1930, p. 1-11, vol. 3. Disponível em:

<https://nbn-resolving.org/urn:nbn:de:gbv:084-11033015075>. Acesso: 04/05/2016.

VON HOHENHEIM, Theophrast. Von den ersten drei Prinzipiis oder Essentiis. In: PEUCKERT, Will-Erich (Ed.). Paracelsus - Werke: Studienausgabe in fünf Bänden. Basel: Schabe Verlag, 2010, p. 322-332, vol.1.

WEBER, F. P. A Portrait Medal of Paracelsus on his Death in 1541. The Numismatic Chronicle And Journal Of The Numismatic Society, Third Series, v. 13, p. $60-71,1893$.

WEBSTER, Charles. Paracelsus Confronts the Saints: Miracles, Healing and the Secularization of Magic. Social History of Medicine, v. 8, n. 3, p. 403421, 1995. Oxford University Press (OUP). Disponível em $<$ http://dx.doi.org/10.1093/shm/8.3.403>.

WITTGENSTEIN, Ludwig. Über Gewissheit. On certainty. Londres: Blackwell, 2004 [1969]. (referências no texto sob o título Da certeza - tradução canônica em português).

ZEKERT, Otto. Theophrast Bombast von Hohenheim [Paracelsus]. Archiv Der Pharmazie, v. 279, n. 9, p. 289-294, 1941. Hoboken: Wiley-Blackwell. Disponível em <http://dx.doi.org/10.1002/ardp.19412790902>.

\section{Resumo}

Apresentamos aqui alguns resultados parciais de investigação tradutória na interface entre história das ciências e divulgação científica, com vistas a: (1) resgatar a importância histórica de Paracelso, cuja obra preparou a passagem 
da Alquimia para várias disciplinas modernas, no que tange a observação e experimentação empíricas; (2) apresentar uma abordagem tradutória para textos de cunho histórico destinados a um público mais amplo, mostrando suas diferenças do pensamento contemporâneo, sem incorrer em conotações exóticas. Elementos centrais são a ideia de escopo e sua incorporação na abordagem funcionalista alemã

Palavras-chave: Paracelso; História das ciências; Tradução científica; Teoria da tradução; Funcionalismo.

\begin{abstract}
This paper presents partial results of a translation research in the interface of history and popularization of sciences, aiming to: (1) rescue the historical importance of Paracelsus, whose work prepared the passage from Alchemy to various modern disciplines, as regards empirical observation and experimentation; (2) present a translational approach to texts of a historical nature intended for a wider audience, showing their differences in face of contemporary thinking, without incurring in exotic connotations. Central elements are the idea of scope and its incorporation into the German functionalist approach.
\end{abstract}

Keywords: Paracelsus; History of science; Scientific translation; Translation theory; Functionalism. 